\title{
Molecular analysis of carcinogen-induced rodent lung tumors: Involvement of microRNA expression and Kras or Egfr mutations
}

\author{
KEIKO YAMAKAWA, TOSHIYA KUNO, NOZOMI HASHIMOTO, MASANAO YOKOHIRA, \\ SATOSHI SUZUKI, YUKO NAKANO, KOUSUKE SAOO and KATSUMI IMAIDA \\ Onco-Pathology, Department of Pathology and Host-Defense, Faculty of Medicine, \\ Kagawa University, Kagawa 761-0793, Japan
}

Received August 10, 2009; Accepted September 10, 2009

DOI: 10.3892/mmr_00000231

\begin{abstract}
Genetic and epigenetic alterations play a key role in lung carcinogenesis, and a high frequency of $K R A S$ and epidermal growth factor receptor $(E G F R)$ mutations have been observed in human lung cancers. Recent evidence indicates that the expression of specific microRNAs (miRNAs) may be involved. In rodent lung carcinogenesis models, Kras mutations are frequently observed, whereas genetic alteration of the Egfr gene is generally rare. Since little is known regarding the involvement of miRNAs in rodent lung carcinogenesis, the present study of miRNA expression levels in the liver and lung during 4-(methylnitrosamino)-1-(3-pyridyl)-1butanone (NNK)- and 2-amino-3,8-dimethylimidazo[4,5- $f$ ] quinoxaline (MeIQx)-induced lung tumorigenesis in A/J mice was conducted. In addition, incidences of Egfr and Kras gene mutations in rat and mouse lung tumors induced by the chemical carcinogens NNK, MeIQx and N-bis(2-hydroxypropyl)nitrosamine (DHPN) were examined. Three miRNAs, let-7a, miR-34c and miR-125a-5p, were selected for attention. In rat lung tumors, one silent mutation was detected in the Egfr gene exon 20 (AAC $\rightarrow$ AAT; N772). Activating mutations of the Kras gene at codon 12 were detected in neoplastic lesions induced by NNK $(5 / 6,83 \%)$, MeIQx $(1 / 1,100 \%)$ and DHPN $(7 / 15,47 \%)$, all resulting in $\mathrm{G} / \mathrm{C} \rightarrow \mathrm{A} / \mathrm{T}$ transitions. NNK or MeIQx administration reduced the expression of miR-125a-5p (MeIQx alone group, 86.3\%;
\end{abstract}

Correspondence to: $\mathrm{Dr}$ Katsumi Imaida, Onco-Pathology, Department of Pathology and Host-Defense, Faculty of Medicine, Kagawa University, 1750-1, Ikenobe, Miki-cho, Kita-gun, Kagawa 761-0793, Japan

E-mail: imaida@med.kagawa-u.ac.jp

Abbreviations: NNK, 4-(methylnitrosamino)-1-(3-pyridyl)-1butanone; MeIQx, 2-amino-3,8-dimethylimidazo[4,5-f]quinoxaline; DHPN, N-bis(2-hydroxypropyl)nitrosamine

Key words: lung carcinogenesis, epidermal growth factor receptor, $K R A S$, microRNA, animal model, gene mutation
MeIQx + NNK group, 83.6\%; p<0.05, at day 15) and let-7a (MeIQx + NNK group, 56.3\%; $\mathrm{p}<0.001$, at day 22) in the liver. miR-34c was up-regulated 3.5-fold with NNK treatment as compared to the control group $(\mathrm{p}<0.001)$. These findings raise the possibility that aberrant expression of miRNA is involved in lung tumorigenesis, at least in its early stages.

\section{Introduction}

Lung cancer is one of the most common causes of cancer mortality worldwide, and non-small cell lung cancers (NSCLCs) account for approximately $80 \%$ of these cases $(1,2)$. Rodent models of lung carcinogenesis are excellent tools for the study of the mechanisms underlying human NSCLC development and for the detection of chemopreventive agents, since the morphologies, histogenesis and molecular characteristics of the induced primary rodent lung tumors are similar to those of humans. The female $\mathrm{A} / \mathrm{J}$ mouse is particularly sensitive to lung carcinogenesis (3), yielding for example a high incidence of tumors upon treatment with 4-(methylnitrosamino)-1-(3-pyridyl)-1-butanone (NNK), a tobacco-specific nitrosamine component of tobacco smoke, or 2-amino-3,8-dimethylimidazo[4,5-f]quinoxaline (MeIQx), a heterocyclic amine that is present as a mutagenic compound in fried beef and beef extracts $(4,5)$. In the F344 rat, N-bis(2hydroxypropyl)nitrosamine (DHPN), an alkylating agent with two propyl chains and a very potent mutagen, causes carcinomas of the lung, thyroid and kidney $(6,7)$. Mutational activation of Kras is observed in these rodent tumors, induced by chemical carcinogens with smoking or nonsmoking factors. Likewise, in human lung cancers, mutations of $K R A S$ have been detected at a high frequency, especially in tobacco smoking patients (7-10). In human lung cancers, recent data have shown that the presence of mutations within the tyrosine kinase (TK) domain of the epidermal growth factor receptor $(E G F R)$ gene is associated with sensitivity to EGFR-TK inhibitors. Such mutations are more frequently observed in Asian, adenocarcinoma and female patients, and in patients with a never-smoking history $(9,11-15)$. However, in animal lung carcinogenesis models, there have been very few reports of mutations within the TK domain of $\operatorname{Eg} f r(16,17)$. 
In human NSCLC patients, survival and response to $E G F R$-TK inhibitors correlate with EGFR mutations, high EGFR copy number, overexpression of EGFR protein and KRAS mutations $(13,18)$. However, it is unclear how mutations of Egfr and other molecular alterations are related to the mechanisms involved in rodent lung carcinogenesis. Not only genetic (e.g., mutations with amino acid substitutions in oncogenes or tumor suppressor genes) but also epigenetic (e.g., DNA methylation, histone modifications and RNA-mediated silencing) factors are known to be important for carcinogenesis (19).

Recently, microRNAs (miRNAs), small non-coding RNAs approximately 22 nucleotides in length, have been recognized as negative regulators through the post-transcriptional regulation of target mRNA expression or protein levels without changes in DNA sequences (20-23). Recent findings indicate that the levels of miRNAs play a key role in diverse cellular processes, including development, cell proliferation, apoptosis, differentiation and stress responses, and that altered expression of specific miRNAs may be involved in tumorigenesis (23-26). Indeed, there have been many studies on the relationship between miRNA expression in human cancer cells or tissues and prognosis, resistance to chemotherapy and invasion or metastasis (23,26-31), though little is known regarding miRNA responses to chemical carcinogen exposure during the early stages of rodent lung carcinogenesis. However, in the lungs of rats exposed to cigarette smoke, 24 miRNAs were found to be down-regulated (32). In particular, the let-7, miR-34 and miR-125 families appear to be associated with human NSCLCs (25). Let-7s have been suggested as tumor suppressors due to their ability to recognize the KRAS and HMGA2 oncogenes as targets for their silencing activity $(33,34)$. The miR-34 family is directly transactivated by $\mathrm{p} 53$, and is thus involved in p53-dependent cell responses to DNA damage (35-38). miR-125 functions in the activation of $E R B B 2$, a preferential heterodimerization partner for $E G F R$ which plays an important role in lung carcinogenesis $(9,39)$.

In the present study, using rodent lung carcinogenesis models, we examined active mutations in exon 1 of the Kras gene and in exons 18-21 of the Egfr gene, which are known to be involved in human lung cancer. Furthermore, in order to determine whether exposure to lung chemical carcinogens influences miRNA expression during the early stages of chemical lung carcinogenesis, we examined levels of let-7a, miR-34c and miR-125a-5p in the livers and lungs of rodents exposed to NNK and MeIQx.

\section{Materials and methods}

Animal treatment. Experimental animals (Experiments 1 and 2) were maintained in the Kagawa University Animal Facility according to the institutional animal care guidelines. The animals were housed in polycarbonate cages with white wood chips for bedding and were given free access to drinking water and a basal CE-2 diet (CLEA Japan Inc., Tokyo, Japan) under controlled conditions of humidity $(60 \pm 10 \%)$, lighting (12-h light/dark cycle) and temperature $\left(24 \pm 2^{\circ} \mathrm{C}\right)$.

Experiment 1. Analysis of Kras and Egfr mutations.

Tissue samples. Formalin fixed paraffin embedded (FFPE) lung neoplastic lesions (hyperplasia, adenoma and adenocarcinoma) were obtained with the following lung carcinogenesis animal models: (i) rat DHPN-induced lung carcinogenesis model (40), in which male 6-week-old F344/DuCrlCrlj rats (Japan Charles River Inc., Kanagawa, Japan) were administered 0.1\% DHPN in drinking water for 2 weeks and sacrificed at week 30; (ii) mouse NNK-induced lung carcinogenesis model (41), in which female 7-week old A/J mice (Japan SLC Inc., Sizuoka, Japan) were administered a single dose of NNK (2 mg/0.1 ml saline/ mouse, i.p.) or an equal volume of saline (vehicle control), then maintained without additional treatment until sacrifice at week 52; (iii) mouse MeIQx-induced lung carcinogenesis model (42), in which female 7-week old A/J mice were fed a diet containing $600 \mathrm{ppm}$ MeIQx during the initial 12-week period, then maintained on a basal diet without MeIQx until sacrifice at week 32 .

The protocols of the experiments were approved by the Animal Care and Use Committee of Kagawa University.

Laser capture microdissection and DNA extraction. DNA was extracted from one $8-\mu \mathrm{m}$-thick unstained paraffin section. FFPE tissue sections were dewaxed twice in xylene, washed in $100 \%$ ethanol and air-dried. Tumor lesions were selectively captured using a Laser Capture Microdissection (LCM) system (LM200; Olympus). Tumors were identified on adjacent sections stained with $\mathrm{H} \& \mathrm{E}$ and were clearly visible on unstained sections. Isolation of DNA from LCM specimens was performed with a Pico Pure DNA Extraction Kit (Arcturus Engineering, Mountain View, CA, USA) according to the manufacturer's protocol.

Polymerase chain reaction and direct DNA sequencing. For mutation analysis of Kras exon 1 and Egfr exons 18-21, lung tumor DNA was amplified by two-step polymerase chain reaction (PCR). Sequences of PCR primers for the amplification of mouse lung tumors are listed in Table I. Sequences of first step PCR primers for the amplification of rat lung tumors were as described by Kitahashi et al (16). The second PCR primers were appended with the sequence of the M13 plasmid (forward, 5'-GTCACGACGTTGTAAAACGAC-3'; reverse, 5'-GCGGATAACAATTTCACACAGG-3') to the 5' end of the first PCR primer. First step PCR was performed in $20 \mu \mathrm{l}$ of reaction mixture consisting of $0.2 \mu \mathrm{M}$ of each primer, $10 \mathrm{X}$ PCR Buffer, $200 \mu \mathrm{M}$ dNTP, 0.5 U Takara Taq ${ }^{\mathrm{TM}}$ HS (Takara Shuzo, Japan) and $1 \mu \mathrm{l}$ of template DNA. The first PCR reaction was performed under the following conditions: initial denaturation at $95^{\circ} \mathrm{C}$ for $30 \mathrm{sec} ; 30$ cycles of $95^{\circ} \mathrm{C}$ for $30 \mathrm{sec}$, $60^{\circ} \mathrm{C}$ for $30 \mathrm{sec}, 72^{\circ} \mathrm{C}$ for $1 \mathrm{~min}$ using the Mastercycler ep gradient $\mathrm{S}$ thermal cycler (Eppendorf). Second step PCR was performed in $50 \mu \mathrm{l}$ of reaction mixture consisting of $0.2 \mu \mathrm{M}$ of each primer, 10X PCR Buffer, $200 \mu \mathrm{M}$ dNTP, $1.25 \mathrm{U}$ Takara Taq ${ }^{\mathrm{TM}} \mathrm{HS}$ and $1 \mu \mathrm{l}$ of the first step PCR product. The second PCR cycling parameters were the same as those of the first step PCR. The second PCR products were purified with SUPREC-02 (Takara Bio Inc., Shiga, Japan) to remove unconsumed dNTPs and primers, and then 1.5- $\mu 1$ aliquots were directly sequenced using a SequiTherm EXCEL ${ }^{\text {TM }}$ II DNA Sequencing Kit (Epicentre Technologies, Madison, WI, USA) with sequence primers labeled with IRD800 by the second PCR (Table I) and a LI-COR 4200 DNA Analyzer (LI-COR Biosciences, Lincoln, NE, USA). 
Table I. Oligonucleotide primers for PCR amplification of DNA from mouse lung tumors (Experiment 1).

$\begin{array}{lll}\text { Gene } & \text { Exon } & \text { Sequence }\left(5^{\prime}-3^{\prime}\right)\end{array}$

First step PCR

Egfr

Kras

Second step PCR and direct DNA sequencing
F GTCACGACGTTGTAAAACGACACCAAGCCCACTTGAGGATA

R GCGGATAACAATTTCACACAGGCACTGGTTCCCAGAAGCCTA

F GTCACGACGTTGTAAAACGACCTGGATCCCAGAAGGTGAGA

R GCGGATAACAATTTCACACAGGGGAAGCAAGATTGACCTTATGAA

F GTCACGACGTTGTAAAACGACTTGGCAGCCAGGAATGTACT

R GCGGATAACAATTTCACACAGGGGCTGTCAGGAAAATGCTTC

F GTCACGACGTTGTAAAACGACTATAAACTTGTGGTGGTTGGCCCT

R GCGGATAACAATTTCACACAGGCCTCTATCGTAGGGTCATACT
F CACGACGTTGTAAAACGAC

R GGATAACAATTTCACACAGG

F, forward primer; $\mathrm{R}$, reverse primer. Underlined is the sequence of the M13 plasmid.

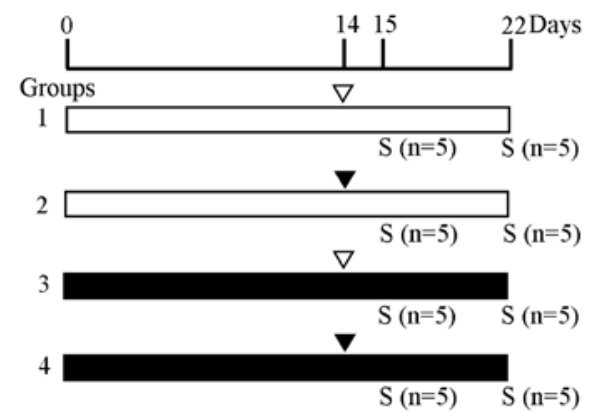

Figure 1. Experimental protocol for Experiment 2. Animals were 7-week-old female A/J mice. $\mathbf{\square}$, MeIQx (600 ppm); $\square$, basal diet (CE-2); $\mathbf{\nabla}$, NNK ( $2 \mathrm{mg} / 0.1 \mathrm{ml} /$ mouse, i.p.); $\nabla$, saline $(0.1 \mathrm{ml} / \mathrm{mouse}$, i.p.); $\mathrm{S}$, sacrifice; $\mathrm{n}$, number of sacrificed mice.

Experiment 2. Expression levels of let-7a, $\mathrm{miR}-34 \mathrm{c}$ and $\mathrm{miR}$ $125 \mathrm{a}$ in A/J mice induced by NNK and MeIQx.

Animals and chemicals. Female 6-week old A/J mice were purchased from Japan SLC Inc. (Shizuoka, Japan). NNK was purchased from Tronto Research Chemicals (Ontario, Canada) and MeIQx from Nard Institute (Nishinomiya, Japan).

Experimental design. The experimental protocol is shown in Fig. 1. A total of 40 mice were divided into 4 groups. Mice in groups 3 and 4 were fed the diet containing 600 ppm MeIQx for 22 days. At day 14, the mice in groups 2 and 4 were given a single dose of NNK (2 mg/0.1 ml saline/mouse i.p.), while those in groups 1 and 3 were given an equal volume of saline (vehicle control). At days 15 and 22 of the experiment (days 1 and 8 after NNK treatment), 5 mice in each group were sacrificed by exsanguination under deep anesthesia. The liver and lung tissues were collected, immersed in RNAlater RNA Stabilization Reagent (Qiagen, Hilden, Germany) and stored at $4^{\circ} \mathrm{C}$ until RNA was extracted.

The protocol of the experiment was approved by the Animal Care and Use Committee.
miRNA extraction and measurement. Total RNA including miRNA was extracted using a miRNeasy Mini Kit (Qiagen). DNA digestion was performed with the RNase-Free DNase Set (Qiagen). The concentration of isolated RNA was determined spectrophotometrically by measuring the absorbance at $260 \mathrm{~nm}$; purity was determined using the ratio of 260/280 nm. Total RNA samples were stored at $-80^{\circ} \mathrm{C}$ until TaqMan analysis.

TaqMan real-time PCR. cDNAs were synthesized from total RNA using a TaqMan MicroRNA Reverse Transcription Kit (Applied Biosystems, Foster City, CA, USA). Total RNA (10 ng) from each sample was reverse transcribed (RT) with a miRNAspecific stem-loop primer supplied in a TaqMan MicroRNA Assay kit (Applied Biosystems) following the manufacturer's protocol. The RT products were diluted 5-fold in nuclease-free water and then amplified by PCR using the TaqMan MicroRNA Assay and analyzed with the StepOnePlus ${ }^{\mathrm{TM}}$ Real-Time PCR System (Applied Biosystems). Real-time PCR reactions were performed in a final volume of $20 \mu \mathrm{l}$, containing $6 \mu \mathrm{l}$ of diluted RT template, $3 \mu \mathrm{l}$ of nuclease-free water, $1 \mu \mathrm{l}$ of $20 \mathrm{X}$ primer/ probe mix from the TaqMan MicroRNA Assay kit (Applied Biosystems) and $10 \mu \mathrm{l}$ of $2 \mathrm{X}$ TaqMan Universal PCR master mix (no AmpErase UNG, Applied Biosystems). The miRNAs used in this study are listed in Table II. Relative levels of miRNA expression were quantified using the relative standard curve method with snoRNA202 as the endogenous control.

Statistical analysis. Relative expression levels were compared using the Kruskal-Wallis test. Differences were considered statistically significant at $\mathrm{p}<0.05$.

\section{Results}

Kras and Egfr gene alterations in lung neoplastic lesions. Mutation analysis of exon 1 of the Kras gene was performed on a total of 7 mouse lung tumors (6 NNK-induced and 1 MeIQx-induced) and 15 DHPN-induced rat lung tumors. 
Table II. Target sequences of let-7a, miR-34c, miR-125a-5p and snoRNA202 using TaqMan real-time PCR (Experiment 2).

\begin{tabular}{|c|c|c|c|c|}
\hline \multirow[t]{2}{*}{ Assay name } & \multirow[t]{2}{*}{ Assay ID } & \multirow[t]{2}{*}{ Target sequence } & \multicolumn{2}{|c|}{ Homology } \\
\hline & & & Homo sapiens & Mus musculus \\
\hline hsa-let-7a & 000377 & UGAGGUAGUAGGUUGUAUAGUU & + & $\stackrel{+}{+}$ \\
\hline hsa-miR-34c & 000428 & AGGCAGUGUAGUUAGCUGAUUGC & + & $\stackrel{+}{+} \underset{(\mathrm{mmu}-\mathrm{miR}-34 \mathrm{c})}{ }$ \\
\hline hsa-miR-125a-5p & 002198 & UCCCUGAGACCCUUUAACCUGUGA & + & $\stackrel{+}{(\mathrm{mmu}-\mathrm{miR}-125 \mathrm{a}-5 \mathrm{p})}$ \\
\hline snoRNA202 & 001232 & $\begin{array}{l}\text { GCUGUACUGACUUGAUGAAAGUAC } \\
\text { UUUUGAACCCUUUUCCAUCUGAUG }\end{array}$ & - & + \\
\hline
\end{tabular}

Table III. Incidences of mutations of the Kras and Egfr genes in lung neoplastic lesions.

\begin{tabular}{|c|c|c|c|c|c|c|c|}
\hline \multirow[t]{2}{*}{ Animal } & \multirow[t]{2}{*}{ Treatment } & \multirow[t]{2}{*}{ Histological type } & \multicolumn{4}{|c|}{ Egfr } & \multirow{2}{*}{$\begin{array}{c}\text { Kras } \\
\text { Exon } 1\end{array}$} \\
\hline & & & Exon 18 & Exon 19 & Exon 20 & Exon 21 & \\
\hline \multirow[t]{2}{*}{ Rats } & \multirow[t]{2}{*}{ DHPN } & Adenoma & $0 / 4$ & $0 / 4$ & $0 / 1$ & $0 / 4$ & $1 / 4 \quad(25 \%)$ \\
\hline & & Adenocarcinoma & $0 / 11$ & $0 / 9$ & $1 / 10(10 \%)$ & $0 / 11$ & $6 / 11(55 \%)$ \\
\hline \multirow[t]{6}{*}{ Mice } & \multirow[t]{2}{*}{ NNK } & Adenoma & $0 / 5$ & $0 / 5$ & - & $0 / 4$ & $2 / 2(100 \%)$ \\
\hline & & Adenocarcinoma & $0 / 4$ & $0 / 3$ & - & $0 / 2$ & $3 / 4 \quad(75 \%)$ \\
\hline & MeIQx & Adenoma & $0 / 3$ & $0 / 3$ & - & $0 / 3$ & $1 / 1(100 \%)$ \\
\hline & \multirow[t]{3}{*}{ Saline } & Hyperplasia & $0 / 1$ & $0 / 1$ & - & $0 / 1$ & - \\
\hline & & Adenoma & $0 / 3$ & $0 / 2$ & - & $0 / 4$ & - \\
\hline & & Adenocarcinoma & $0 / 3$ & $0 / 3$ & - & $0 / 2$ & - \\
\hline
\end{tabular}

-, not examined.

Table IV. Mutation patterns for the Kras and Egfr genes.

\begin{tabular}{|c|c|c|c|c|c|}
\hline Gene & Exon & Animal & Nucleotide change & Amino acid change & Frequency \\
\hline \multirow[t]{2}{*}{ Kras } & Exon 1 & Mice & $\mathrm{GG} T \rightarrow \mathrm{G} \underline{\mathrm{AT}}$ & G12D & $7 / 7$ \\
\hline & & Rats & $\mathrm{G} \underline{\mathrm{GT}} \rightarrow \mathrm{G} \underline{\mathrm{AT}}$ & G12D & $6 / 6$ \\
\hline Egfr & Exon 20 & Rats & $\mathrm{AAC} \rightarrow \mathrm{AAT}$ & N772 & $1 / 1$ \\
\hline
\end{tabular}

Activating mutations of the Kras gene at codon 12 were detected in neoplastic lesions induced by NNK (5/6; 83\%), MeIQx $(1 / 1 ; 100 \%)$ and DHPN $(7 / 15 ; 47 \%)$. All mutations were $\mathrm{G} / \mathrm{C} \rightarrow \mathrm{A} / \mathrm{T}$ transitions (Tables III and IV).

Mutations of the Egfr gene in exons 18, 19 and 21 were examined in a total of 20 mouse lung tumors (9 NNK-induced, 3 MeIQx-induced and 8 spontaneous). It was not possible to perform analysis of exon 20 of the Egfr gene due to insufficient lung tumor DNA. The number of samples that were analyzed by DNA sequencing were as follows: exon 18, 19 tumors; exon 19, 17 tumors; exon 21, 16 tumors. Egfr mutations were not detected in mouse lung tumors. On the other hand, mutation analysis of exons 18-21 of the Egfr gene in a total of 15 DHPN-induced rat lung tumors (number of samples analyzed by DNA sequencing: exon 18, 15 tumors; exon 19, 13 tumors; exon 20, 11 tumors; exon 21, 15 tumors) revealed one silent mutation in exon $20(\mathrm{AA} \underline{\mathrm{C}} \rightarrow \mathrm{AAT}$; N772) (Tables III and IV and Fig. 2).

MiRNA expression in livers and lungs of A/J mice treated with NNK or MeIQx. Fig. 3 shows the relative expression of let-7a, miR-34c and 125a-5p in mouse livers. In the liver, mean relative expression of miR-125a-5p was significantly reduced in the groups receiving MeIQx alone and NNK and MeIQx in combination as compared with the control group at day 15 ( 1 day after NNK treatment) [0.97 \pm 0.09 (86.3\%), $\mathrm{p}<0.05 ; 0.94 \pm 0.10$ (83.6\%), $\mathrm{p}<0.01$ vs. $1.12 \pm 0.07]$. At day 22 ( 8 days after NNK treatment), the mean relative expression 

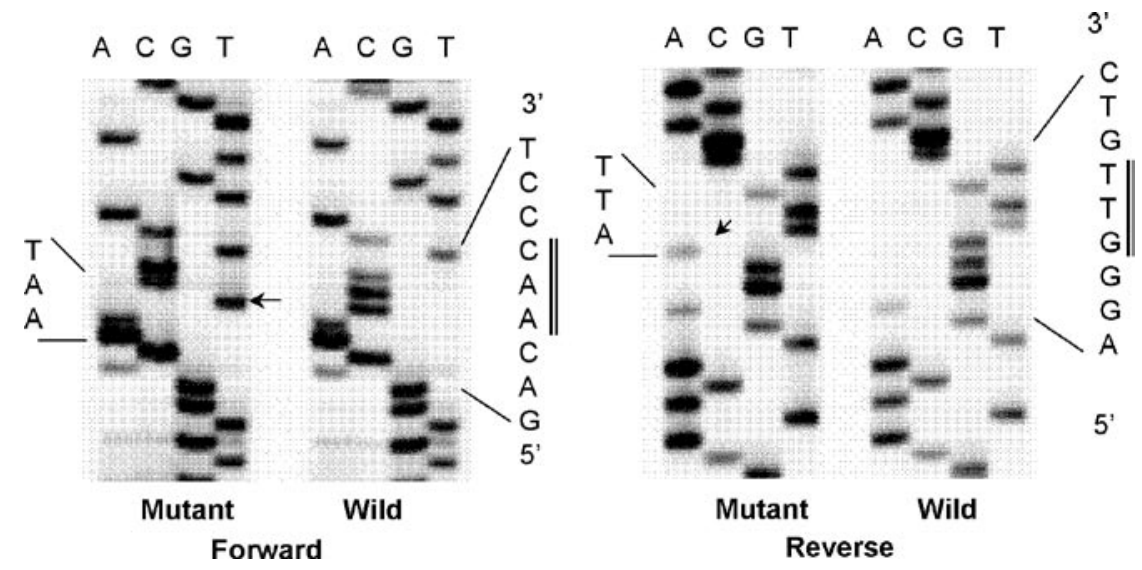

Figure 2. Egfr gene mutations in rat adenocarcinomas induced by DHPN. Arrows indicate mutation bands (AAC $\rightarrow$ AAT at codon 772 ).

let-7a

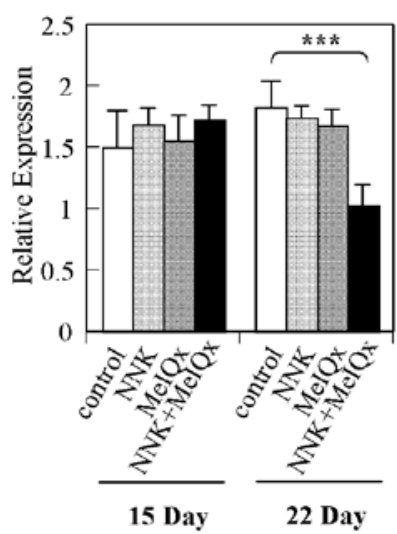

miR-34c

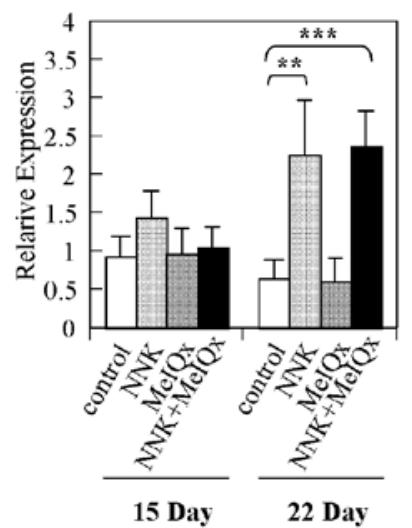

miR-125a-5p

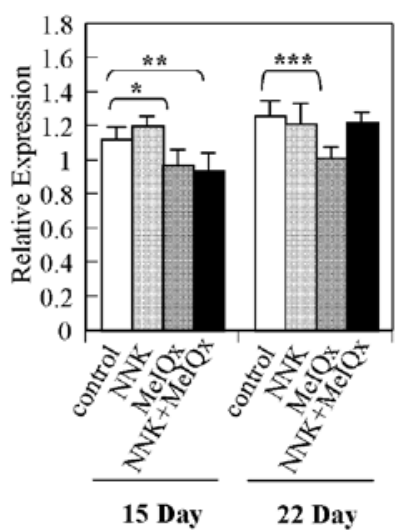

Figure 3. Relative expression levels of miRNAs (let-7a, miR-34c and miR-125a-5p) in livers at days 15 and 22 (days 1 and 8 after NNK treatment) as measured by TaqMan real-time PCR. The relative levels of miRNA expression were quantified using the relative standard curve method with snoRNA202 as the endogenous control. Shown are averages and standard deviations (error bars). ${ }^{*} \mathrm{p}<0.05 ;{ }^{* *} \mathrm{p}<0.01 ;{ }^{* * * *} \mathrm{p}<0.001$, significantly different compared to the control group.
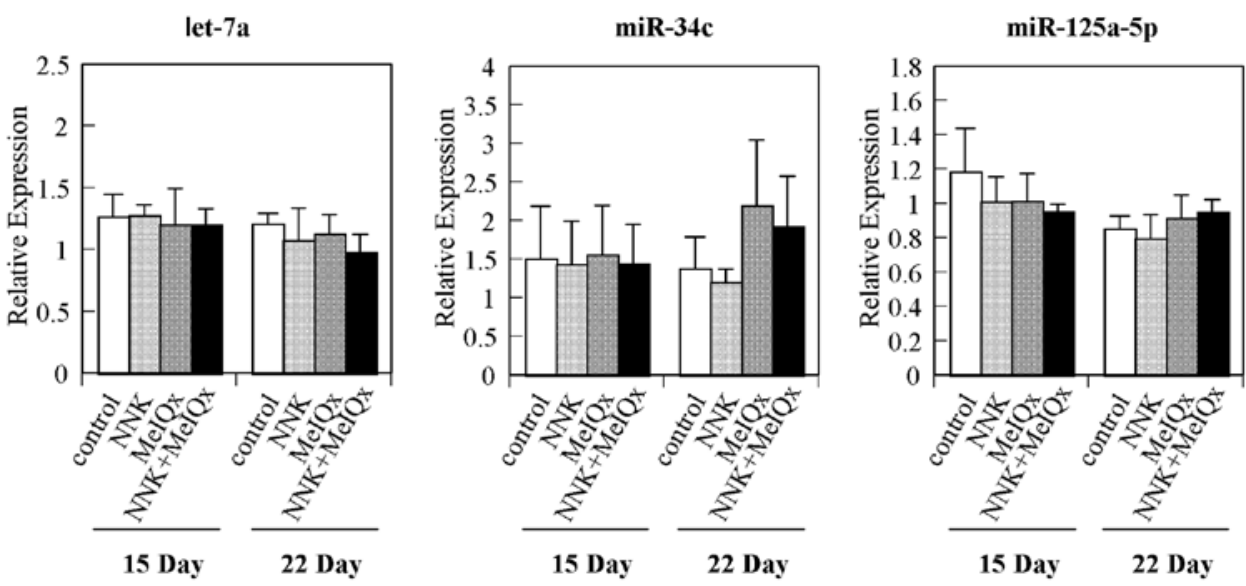

Figure 4. Relative expression levels of miRNAs (let-7a, miR-34c and miR-125a-5p) in lungs at days 15 and 22 (1 and 8 after NNK treatment) as measured by TaqMan real-time PCR. The relative levels of miRNA expression were quantified using the relative standard curve method with snoRNA202 as the endogenous control. Shown are averages and standard deviations (error bars). No significant differences were observed.

of miR-125a-5p was significantly reduced to $80 \%$ only in the group receiving MeIQx alone as compared with the control group $(1.01 \pm 0.06$ vs. $1.26 \pm 0.08, \mathrm{p}<0.001)$. Similarly, let-7a was significantly reduced to $56.3 \%$ in the group administered the combination of NNK and MeIQx as compared with the control group $(1.03 \pm 0.17$ vs. $1.83 \pm 0.21, \mathrm{p}<0.001)$ at day 22 (8 days after NNK treatment). On the other hand, the mean relative expression of miR-34c in the liver was significantly 
increased by 3.5 -fold with NNK alone as compared with the control group $(2.26 \pm 0.71$ vs. $0.65 \pm 0.24, \mathrm{p}<0.01)$ at day 22 (8 days after NNK treatment). Similarly, with the NNK and MeIQx combination, the expression level of miR-34c was increased 3.6-fold as compared with the control group $(2.36 \pm 0.47$ vs. $0.65 \pm 0.24, \mathrm{p}<0.001)$. At day 15 , the expression level of miR-34c in the group administered NNK alone was also up-regulated 1.5 -fold, but without attaining statistical significance $(\mathrm{p}=0.08)$.

In the lung, there was no significant variation in the expression levels of these miRNAs at either day 15 or day 22 (Fig. 4).

\section{Discussion}

In the present study, a mutation in the Egfr gene exon 20 was detected in one rat lung adenocarcinoma induced by DHPN, but was a silent mutation (AAC $\rightarrow$ AAT; N772). Egfr mutations of rodent lung carcinogenesis have only been reported under special conditions, such as X-ray irradiation (16), and in genetically engineered animals with Oggl gene deficiency (17). To our knowledge, this is the first demonstration of an Egfr mutation in chemical lung carcinogenesis in a nongenetically engineered animal. The frequency of EGFR mutation in human NSCLCs is relatively high (26-40\% in Asian patients and $2-12 \%$ in non-Asian patients). In one animal model, urethane-induced lung adenomas in male A/J mice were inhibited by EGFR-TK domain inhibitor, despite a lack of mutation in the Egfr-TK domain, presumably due to activated Egfr signaling (43). Such activation of the Egfr signaling pathway caused by genetic or epigenetic mechanisms without somatic mutations of Egfr may be involved in the growth of lung tumors in both humans and animals. Here, we detected mutations in codon 12 of the Kras gene (NNK, 83\%; MeIQx, 100\%; DHPN, 47\%), with similar incidences as those previously reported (16). Mutations of the Kras gene exons 1 and 2 have been frequently identified in rodent lung carcinogenesis models using chemical carcinogens, as well as in human lung cancer in smokers. Recently, it was suggested that RAS oncogenic signaling is caused not only by KRAS activating mutations, but also by a reduction in let-7 $(23,26,33)$, and the expression levels of let-7 family members were found to be reduced in human lung cancers $(28,44)$. In the lungs of mice expressing a G12D activating mutation for the Kras gene, delivery of let-7a to the lung reduced tumor formation (45). In the present study, let-7a in the liver was down-regulated with combined administration of NNK and MeIQx at 22 days (8 days after NNK treatment). In addition, MeIQx induced the down-regulation of miR-125a-5p in the liver, while NNK treatment was without effect. In contrast, only NNK clearly induced up-regulated miR-34c in the liver, and MeIQx was without influence. These results suggest that changes in let-7a, miR-34c and miR-125a-5p expression may be involved in the early stages of tumorigenesis induced by chemicals, and with possible carcinogen specificity. This could be due to differences in the mechanisms of action of carcinogens.

There have been numerous reports pointing to a relationship between the miR-34 family and carcinogenesis. In an Fe-NTAinduced rat renal carcinogenesis model, altered expression of miR-34a was observed within a few weeks of commencing
Fe-NTA treatment (46). The lymphocytes of patients with chronic lymphomatic leukemia were found to demonstrate the up-regulation of miR-34a at $16 \mathrm{~h}$ after $\gamma$-irradiation, causing DNA damage (27). Thus, the miR-34 family may be rapidly induced by DNA-damaging agents. Recent studies suggest it plays an important role in the regulation of the p53 pathway, since: (i) the miR-34 family is up-regulated by the activation of $\mathrm{p} 53$ resulting in the induction of apoptosis by BCL2 and E2F3; and (ii) p53 induces cell cycle arrest through p21, and apoptosis through Bax $(23,26,27,37)$. In our previous study, we examined the expression levels of mRNAs involved in p53 signaling pathways (cyclin G1, p21, Bax and Mdm2) in the livers and lungs of female $\mathrm{A} / \mathrm{J}$ mice exposed to NNK. In the livers, up to 10 -fold up-regulation was observed after 1 day. At 14 days after NNK treatment, mRNAs of cyclin G1, Bax and Mdm2 were up-regulated approximately 2-fold, and p21 mRNA was up-regulated 6-fold as compared with the control group (unpublished data). These results raise the possibility that NNK induces the activation of the $\mathrm{p} 53$ pathway during the early stages of tumorigenesis (during cancer initiation, before neoplastic transformation).

In human cancer, deleted chromosome regions often contain miRNA genes, causing low levels of expression (25). In animal carcinogenesis models, exposure to carcinogens may also result in a reduction in miRNA levels. In the lungs of Sprague Dawley rats exposed to cigarette smoke for 4 weeks, 24 miRNAs including members of the let-7, miR-34 and miR-125 families were found to be down-regulated by at least 3 -fold (32). In the lungs of male F344 rats receiving 10 ppm of NNK in drinking water, a number of miRNAs including miR-34b were also down-regulated as compared with the control group 1 week after the initiation of treatment (47). These results suggest that a reduction in specific miRNAs is involved in the early stages of tumorigenesis. However, in this study, we did not detect any significant differences in the expression levels of let-7a, miR-125a-5p and miR-34c in the lung, which is the target organ of NNK and MeIQx. This result requires clarification.

In conclusion, the present examination of genetic and epigenetic mechanisms of rodent lung carcinogenesis revealed: (i) a high incidence of Kras gene mutations, but only one mutation in the Egfr gene exons 18-21; and (ii) changes in the miRNA expression levels of let-7a, miR-34c and miR-125a-5p during the early stages of tumorigenesis. The sequences of a large number of miRNAs are conserved between humans and rodents, and it may therefore be possible that alterations of specific miRNAs involved in human lung cancer may also be detected in a rodent lung carcinogenesis model. In order to study the participation of miRNAs in tumor initiation and progression, further studies are clearly warranted with a focus on any relationships with the activation of the Egfr and Kras genes at different stages of tumor induction.

\section{Acknowledgements}

This work was supported by Grants-in Aid for Cancer Research from the Ministry of Health, Labour and Welfare of Japan. We thank Dr. Malcolm A. Moore, a native English-speaking scientist, for his help in the preparation and critical reading of the manuscript. 


\section{References}

1. Travis WD, Travis LB and Devesa SS: Lung cancer. Cancer 75: 191-202, 1995.

2. Sun S, Schiller JH and Gazdar AF: Lung cancer in never smokers - a different disease. Nat Rev Cancer 7: 778-790, 2007.

3. Imaida K, Yokohira M and Kuno T: Detection of carcinogenic and modifying potentials by test compounds using a mouse lung carcinogenesis bioassay. Journal of Toxicologic Pathology 20: 117-123, 2007.

4. Peterson LA and Hecht SS: O6-methylguanine is a critical determinant of 4-(methylnitrosamino)-1-(3-pyridyl)-1-butanone tumorigenesis in A/J mouse lung. Cancer Res 51: 5557-5564, 1991.

5. Sugimura T, Wakabayashi K, Nakagama $H$ and Nagao M: Heterocyclic amines: Mutagens/carcinogens produced during cooking of meat and fish. Cancer Sci 95: 290-299, 2004.

6. Konishi Y, Kondo H, Ikeda T, Kawabata A, Shoji Y and Denda A: Effect of dose on the carcinogenic activity of orally administered N-bis(2-hydroxypropyl)nitrosamine in rats. Gann 69: 573-577, 1978.

7. Kitahori Y, Naito H, Konishi N, Ohnishi T, Shirai T and Hiasa Y: Frequent mutations of Ki-ras codon 12 in N-bis (2-hydroxypropyl)nitrosamine-initiated thyroid, kidney and lung tumors in Wistar rats. Cancer Lett 96: 155-161, 1995.

8. Fukuyama Y, Mitsudomi T, Sugio K, Ishida T, Akazawa K and Sugimachi K: K-ras and p53 mutations are an independent unfavourable prognostic indicator in patients with non-small cell lung cancer. Br J Cancer 75: 1125-1130, 1997.

9. Gazdar AF, Shigematsu H, Herz J and Minna JD: Mutations and addiction to EGFR: the Achilles 'heal' of lung cancers? Trends Mol Med 10: 481-486, 2004.

10. Ronai ZA, Gradia S, Peterson LA and Hecht SS: G to A transitions and $\mathrm{G}$ to $\mathrm{T}$ transversions in codon 12 of the $\mathrm{Ki}$-ras oncogene isolated from mouse lung tumors induced by 4-(methylnitrosamino)-1-(3pyridyl)-1-butanone (NNK) and related DNA methylating and pyridyloxobutylating agents. Carcinogenesis 14: 2419-2422, 1993.

11. Lynch TJ, Bell DW, Sordella R, et al: Activating mutations in the epidermal growth factor receptor underlying responsiveness of non-small cell lung cancer to gefitinib. N Engl J Med 350: 2129-2139, 2004

12. Paez JG, Janne PA, Lee JC, et al: EGFR mutations in lung cancer: correlation with clinical response to gefitinib therapy. Science 304: 1497-1500, 2004.

13. Berardi R, Verdecchia L, Paolo MD, et al: Women and lung cancer: clinical and molecular profiling as a determinate for treatment decisions: a literature review. Crit Rev Oncol Hematol 69: 223-236, 2009.

14. Yamamoto H, Toyooka S and Mitsudomi T: Impact of EGFR mutation analysis in non-small cell lung cancer. Lung Cancer 63: 315-321, 2009.

15. Pao W, Miller V, Zakowski M, et al: EGF receptor gene mutations are common in lung cancers from 'never smokers' and are associated with sensitivity of tumors to gefitinib and erlotinib. Proc Natl Acad Sci USA 101: 13306-13311, 2004.

16. Kitahashi T, Takahashi M, Yamada Y, et al: Occurrence of mutations in the epidermal growth factor receptor gene in X-rayinduced rat lung tumors. Cancer Science 99: 241-245, 2008.

17. Igarashi M, Watanabe M, Yoshida M, et al: Enhancement of lung carcinogenesis initiated with 4-(N-hydroxymethylnitrosamino)-1 -(3-pyridyl)-1-butanone by Ogg1 gene deficiency in female, but not male, mice. J Toxicol Sci 34: 163-174, 2009.

18. Zhang $X$ and Chang A: Molecular predictors of EGFR-TKI sensitivity in advanced non-small cell lung cancer. Int $\mathrm{J}$ Med Sci 5: 209-217, 2008.

19. Jones PA and Baylin SB: The fundamental role of epigenetic events in cancer. Nat Rev Genet 3: 415-428, 2002

20. Bartel DP: MicroRNAs: genomics, biogenesis, mechanism and function. Cell 116: 281-297, 2004.

21. Gregory RI, Chendrimada TP, Cooch N and Shiekhattar R: Human RISC couples microRNA biogenesis and posttranscriptional gene silencing. Cell 123: 631-640, 2005.

22. Carthew RW: Gene regulation by microRNAs. Curr Opin Genet Dev 16: 203-208, 2006.

23. Ryazansky SS and Gvozdev VA: Small RNAs and cancerogenesis. Biochemistry (Mosc) 73: 514-527, 2008.

24. Lagos-Quintana M, Rauhut R, Lendeckel W and Tuschl T: Identification of novel genes coding for small expressed RNAs. Science 294: 853-858, 2001.
25. Calin GA, Sevignani C, Dumitru CD, et al: Human microRNA genes are frequently located at fragile sites and genomic regions involved in cancers. Proc Natl Acad Sci USA 101: 2999-3004, 2004.

26. Negrini M, Nicoloso MS and Calin GA: MicroRNAs and cancer-new paradigms in molecular oncology. Curr Opin Cell Biol 21: 470-479, 2009.

27. Zenz T, Mohr J, Eldering E, et al: miR-34a as part of the resistance network in chronic lymphocytic leukemia. Blood 113: 3801-3808, 2009.

28. Inamura $\mathrm{K}$, Togashi $\mathrm{Y}$, Nomura $\mathrm{K}$, et al: let-7 microRNA expression is reduced in bronchioloalveolar carcinoma, a noninvasive carcinoma, and is not correlated with prognosis. Lung Cancer 58: 392-396, 2007.

29. Rosell R, Wei J and Taron M: Circulating MicroRNA signatures of tumor-derived exosomes for early diagnosis of non-small cell lung cancer. Clin Lung Cancer 10: 8-9, 2009.

30. Ma L, Teruya-Feldstein J and Weinberg RA: Tumour invasion and metastasis initiated by microRNA-10b in breast cancer. Nature 449: 682-688, 2007.

31. Yanaihara N, Caplen N, Bowman E, et al: Unique microRNA molecular profiles in lung cancer diagnosis and prognosis. Cancer Cell 9: 189-198, 2006.

32. Izzotti A, Calin GA, Arrigo P, Steele VE, Croce CM and De Flora S: Down-regulation of microRNA expression in the lungs of rats exposed to cigarette smoke. FASEB J 23: 806-812, 2009.

33. Johnson SM, Grosshans H, Shingara J, et al: RAS is regulated by the let-7 microRNA family. Cell 120: 635-647, 2005.

34. Lee YS and Dutta A: The tumor suppressor microRNA let-7 represses the HMGA2 oncogene. Genes Dev 21: 1025-1030, 2007.

35. Tarasov V, Jung P, Verdoodt B, et al: Differential regulation of microRNAs by $\mathrm{p} 53$ revealed by massively parallel sequencing: miR-34a is a p53 target that induces apoptosis and G1-arrest. Cell Cycle 6: 1586-1593, 2007.

36. Bommer GT, Gerin I, Feng Y, et al: p53-mediated activation of miRNA34 candidate tumor-suppressor genes. Curr Biol 17: 1298-1307, 2007.

37. He L, He X, Lim LP, et al: A microRNA component of the p53 tumour suppressor network. Nature 447: 1130-1134, 2007.

38. Raver-Shapira N, Marciano E, Meiri E, et al: Transcriptional activation of miR-34a contributes to p53-mediated apoptosis. Mol Cell 26: 731-743, 2007.

39. Scott GK, Goga A, Bhaumik D, Berger CE, Sullivan CS and Benz CC: Coordinate suppression of ERBB2 and ERBB3 by enforced expression of micro-RNA miR-125a or miR-125b. J Biol Chem 282: 1479-1486, 2007.

40. Yokohira M, Hashimoto N, Yamakawa K, et al: Lung Carcinogenic Bioassay of $\mathrm{CuO}$ and $\mathrm{TiO} 2$ Nanoparticles with Intratracheal Instillation Using F344 Male Rats. Journal of Toxicologic Pathology 22: 71-78, 2009.

41. Takeuchi H, Saoo K, Matsuda Y, et al: 8-Methoxypsoralen, a potent human CYP2A6 inhibitor, inhibits lung adenocarcinoma development induced by 4-(methylnitrosamino)-1-(3-pyridyl)1-butanone in female A/J mice. Molecular Medicine Reports 2: 585-588, 2009.

42. Matsuda Y, Takeuchi H, Yokohira M, et al: Enhancing effects of high fat diet 2-amino-3,8-dimethylimidazo[4,5-f]quinoxalineinduced lung tumorigenesis in female $\mathrm{A} / \mathrm{J}$ mice. Mol Med Rep 2: 701-706, 2009.

43. Zerbe LK, Dwyer-Nield LD, Fritz JM, et al: Inhibition by erlotinib of primary lung adenocarcinoma at an early stage in male mice. Cancer Chemother Pharmacol 62: 605-620, 2008.

44. Takamizawa J, Konishi H, Yanagisawa K, et al: Reduced expression of the let-7 microRNAs in human lung cancers in association with shortened postoperative survival. Cancer Res 64: 3753-3756, 2004.

45. Esquela-Kerscher A, Trang P, Wiggins JF, et al: The let-7 microRNA reduces tumor growth in mouse models of lung cancer. Cell Cycle 7: 759-764, 2008.

46. Dutta KK, Zhong Y, Liu YT, et al: Association of microRNA-34a overexpression with proliferation is cell type-dependent. Cancer Sci 98: 1845-1852, 2007

47. Kalscheuer S, Zhang X, Zeng Y and Upadhyaya P: Differential expression of microRNAs in early-stage neoplastic transformation in the lungs of F344 rats chronically treated with the tobacco carcinogen 4-(methylnitrosamino)-1-(3-pyridyl)-1-butanone. Carcinogenesis 29: 2394-2399, 2008. 